\title{
AC 2009-1673: PRACTICAL DEMONSTRATION UNITS, USING COMMON COMPONENTS, FOR AN INTRODUCTORY THERMODYNAMICS COURSE
}

\section{Michael Plumley, United States Coast Guard Academy}

LCDR Michael Plumley is an Assistant Professor, and 1998 graduate, of the Mechanical Engineering program at the U.S. Coast Guard Academy. He has served as coordinator for a variety of courses, including Capstone Design, Machine Design, Mechanisms, Heat Transfer, and Modeling and Control of Dynamic Systems. He holds Master of Science degrees in both Mechanical Engineering and Naval Architecture and Marine Engineering from the Massachusetts Institute of Technology, and he is a registered Professional Engineer in the State of Connecticut. His previous assignments included service as shipboard engineer and port engineer.

\section{Andrew Foley, United States Coast Guard Academy}

Dr Andy Foley is an Associate Professor at the U.S Coast Guard Academy. Previously he has taught at Ohio University, St Martins University, Washington and Coventry University in the U.K where he was also the head of the Aerospace Technology program. Dr Foley obtained his $\mathrm{PhD}$ from Cranfield University in the area of Turbomachinery and engineering mechanics. Before entering Academia Professor Foley worked as a Principal Engineer and technical consultant for firms such as Rolls Royce, BMW and Alstom. His two main areas of instruction are Thermofluids and Mechanical Design and his research is directed towards the design of assorted hybrid alternative energy systems.

\section{Earnest Greene, US Coast Guard Academy}




\title{
Practical Demonstration Units, Using Common Components, For An Introductory Thermodynamics Course
}

\begin{abstract}
The enhancement of an introductory thermodynamics course, using devices constructed from common lab components, is presented and discussed. The devices were developed using spare parts and materials readily available to provide practical demonstrations in the classroom. The devices include: a simple water bottle rocket launcher used to demonstrate the conservation of mass; a space heater and plywood box used to demonstrate steady state heat transfer and energy conservation; and an air piston, accumulator, and compressor system for demonstrating boundary work. Specifications are presented with associated costs. Class exercises used with the demonstration units are described in detail. The demonstrations, with exercises, each require one hour of lecture, and were used in an accredited thermodynamics course. The course is scheduled for 2.5 lecture hours per week, with no lab, presenting an ideal venue for short demonstrations.
\end{abstract}

\section{Introduction}

The US Coast Guard Academy's three credit introductory thermodynamics course does not include a dedicated lab. The course is required of all students seeking mechanical, civil, or naval architecture and marine engineering degrees. Many electrical engineering and marine science students take the course as an elective. The need for a lab, along with the complexities of incorporating one into already crowded student schedules, was recently addressed in a local program review. The issue of balancing thermodynamic instruction and student course load is not unique to this institution [1]. To account for the lack of lab time, the authors, who were new to teaching this course at this institution, endeavored to introduce hands on demonstrations during typical lectures. This resulted in the design, construction, and use of three stand alone demonstration units. The devices include: a simple water bottle rocket launcher used to demonstrate the conservation of mass and ideal gas law; a space heater and plywood box to demonstrate steady state heat transfer and the conservation of energy; and an air piston, accumulator, and compressor system for demonstrating boundary work.

Effective labs can be introduced without a significant cost increase. Professional lab kits may be expensive, with different units available commercially for thousands of dollars. This work focuses on low cost alternatives, a topic which has received attention in recent literature. Edwards presents a simple experiment using a hair dryer and thermocouples for demonstrating the first law [2]. Volino and Smith introduce a low cost lab consisting of a simple dynamometer and small spark ignition engine, such as that which may be found on a lawnmower [3]. Similar engines are also used at the Coast Guard Academy for introductory instruction on internal combustion engines and mechanisms. A variety of labs, some involving commonly found devices, and others using professionally designed units, may be found in [4]. Alvarado encourages students to design their own experiments, presenting a recent example evaluating a refrigerator coefficient of performance [5]. For many years students at the Coast Guard Academy 
have designed their own low cost experiments in a follow on course in experimental methods in fluid and thermal sciences [6-8]. Low cost design, build, and test exercises are also required in another follow on course in thermal systems design [9-10].

The success of the units described in this work ensures they will be used in future classes. These devices, combined with several real world problems inspired by student interest, contributed to very positive feedback regarding the students' confidence in their ability to apply course concepts beyond the classroom.

\section{Water bottle rocket launcher and conservation of mass}

The soda bottle rocket launcher is widely used for educational and recreational purposes. Several references are available online detailing different launching mechanisms. The device described here lends itself to a unique exercise which grabs student attention while investigating the conservation of mass.

\section{Description}

The launcher, shown in figures 1 and 2, incorporates a common foot pump, as well as a frame designed to allow for convenient bottle loading. Figure 3 shows how the device's unique design allows users to load bottles without spilling excess water. Less complex mechanisms may be suitable. Figure 4 depicts a CAD model of the bracket which secures the bottle to the launcher. The bracket is designed to provide an interference fit against the collar found on common bottles. It is supported by a housing constructed from a common electrical junction box. A multi-purpose foot pump is used, yet any pump with a readily estimable geometry and gauge would be suitable. A bicycle tube valve stem is fitted to the base and housing.

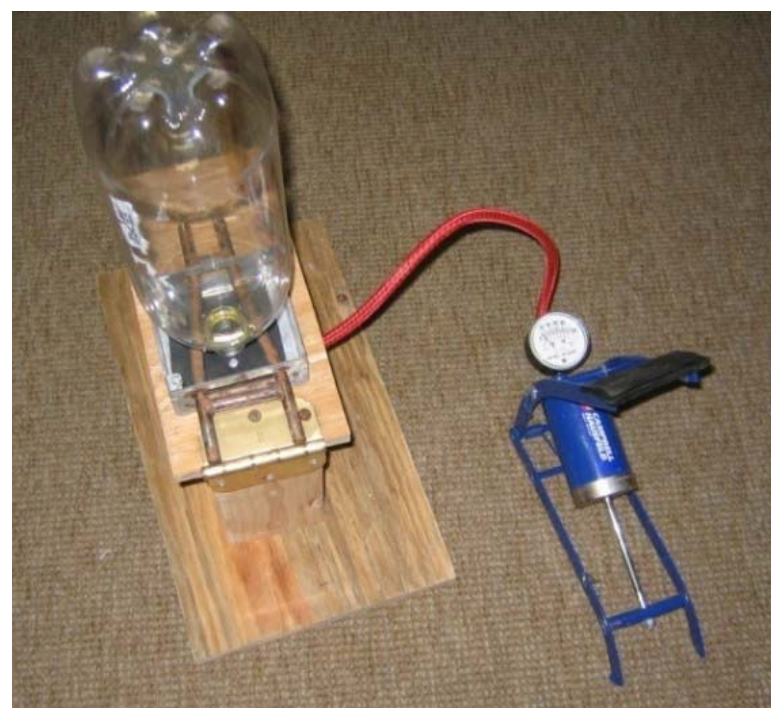

Figure 1 Water bottle rocket launcher.

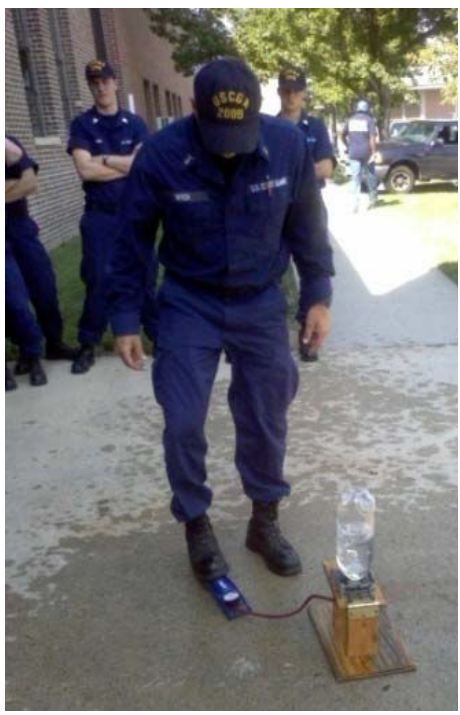

Figure 2 A student counts pump cycles prior to launch. 


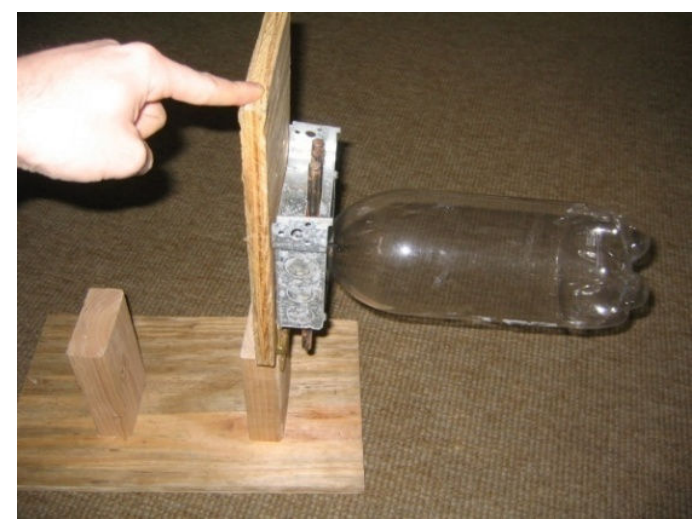

Figure 3 The hinged platform prevents water from spilling during loading.

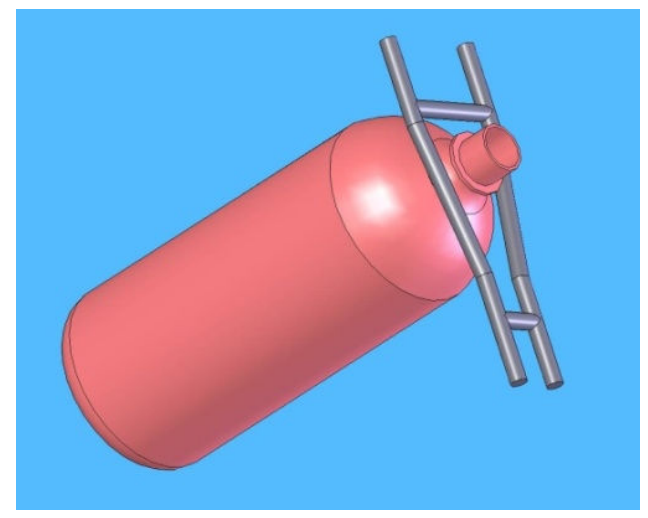

Figure 4 This CAD model shows how the bracket slides over the bottle.

\section{Class exercise}

Students are shown a short video of a water bottle launch while operation of the device is explained. Next, they are divided into small groups and provided with a ruler and two liter bottle. They are asked to guess, without calculation, the number of pumps required to raise the pressure to 25 psig. They are then instructed to estimate that number using simple measurements and calculations. A sketch of the system is shown in figure 5 .

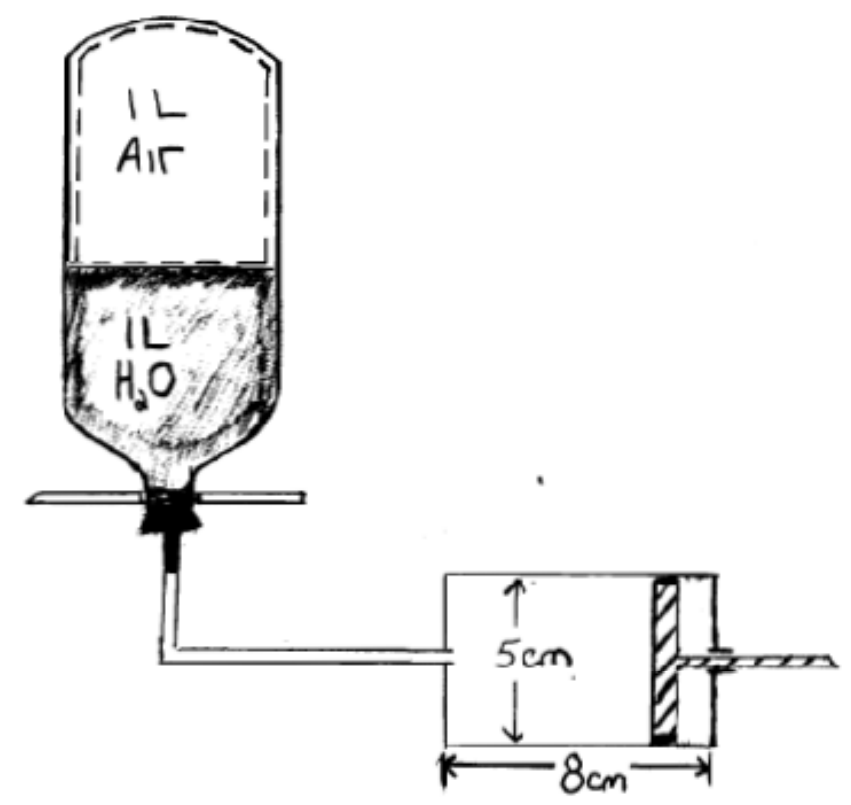

Figure 5 Bottle launcher configuration, with approximate pump dimensions.

Student results are recorded and the device is taken outdoors, where each group loads a bottle and counts the number of pump cycles until the desired pressure is reached. The bottle is then fired, a crowd favorite. 


\section{Results}

The experiment was conducted with four classes. The results from two classes, each consisting of four groups, are given in table 1. Only the first class' guess values are available. The guess portion of the exercise demonstrates the perils of uninformed guessing. In most cases the student calculated estimate was considerably more accurate than the guess. The results may be used to discuss the advantages of using multiple teams to take measurements, as the average estimated and actual values converge as expected.

Table 1 Number of cycles to reach 25 psig during water bottle rocket exercise.

\begin{tabular}{|c|c|c|c|c|c|}
\hline Group & Guess & Estimate & Actual & $\begin{array}{c}\text { \% Error } \\
\text { Guess vs Act }\end{array}$ & $\begin{array}{c}\text { \% Error } \\
\text { Est vs Act }\end{array}$ \\
\hline 1 & 54 & 22 & 24 & $125 \%$ & $8 \%$ \\
\hline 2 & 55 & 27 & 23 & $139 \%$ & $17 \%$ \\
\hline 3 & 18 & 23 & 21 & $14 \%$ & $10 \%$ \\
\hline 4 & 21 & 19 & 22 & $9 \%$ & $13 \%$ \\
\hline 5 & & 24 & 25 & & $4 \%$ \\
\hline 6 & & 28 & 25 & & $12 \%$ \\
\hline 7 & & 30 & 25 & & $20 \%$ \\
\hline 8 & & 22 & 25 & & $12 \%$ \\
\hline Average & & 24.5 & 23.9 & $55 \%$ & $3 \%$ \\
\hline
\end{tabular}

\section{Space heater and steady state heat transfer}

This exercise provides students with the opportunity to visualize different control volumes and investigate the relationship between their heat transfer and engineering thermodynamics courses. A space heater is enclosed in a simple plywood box. The power drawn by the heater, along with the inside and outside air temperatures, is measured and recorded until steady state temperatures are achieved. The results are then compared to those from a basic steady state heat transfer analysis.

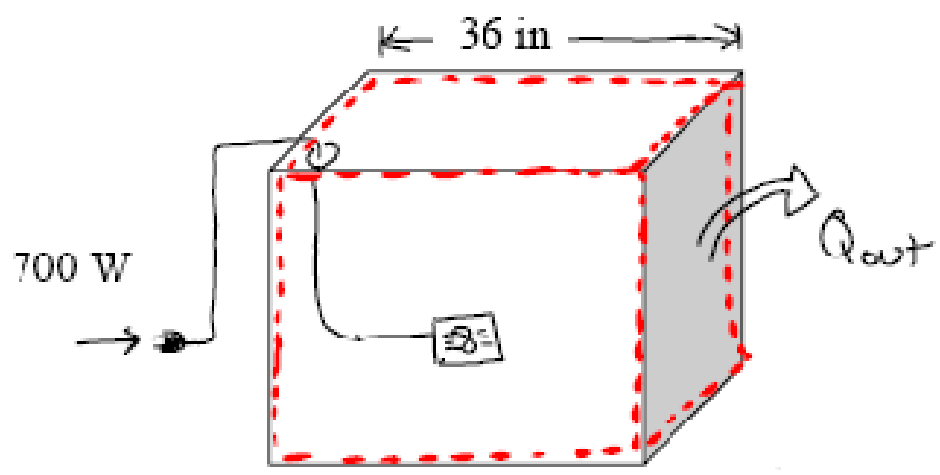

Figure 6 Space heater and control volume configuration. 


\section{Description}

A one cubic yard plywood box is constructed with $1 / 2$ inch thick plywood as shown in figure 7 . Another piece of wood is used to cover the access hole during the demonstration. A common household space heater is placed in the box as shown in figure 8 . In this case a space heater with integrated fan was used. This allows instructors to highlight the fact that the individual fan and heating element power demands need not be investigated if a convenient control volume is chosen. A multi-meter, with ammeter, is used to measure the voltage and current for estimating the electrical power entering the control volume. A handheld data acquisition system, with thermocouple, was used to measure the temperature. For many of the students this is their first introduction to these measuring tools, allowing for additional instruction.

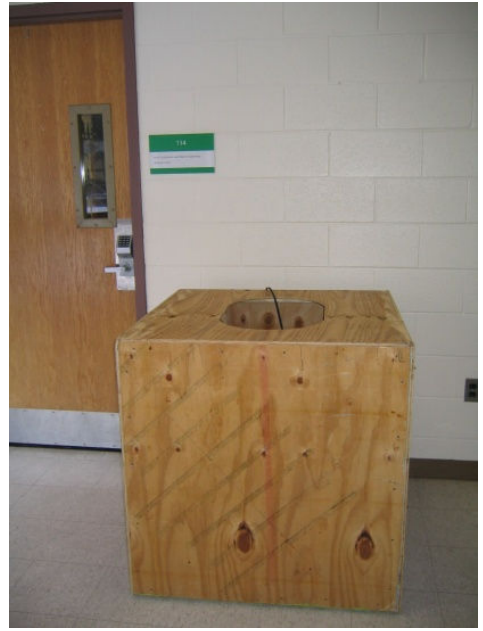

Figure 7 A simple plywood box provides an enclosure which can be quickly heated to steady state during a lecture period.

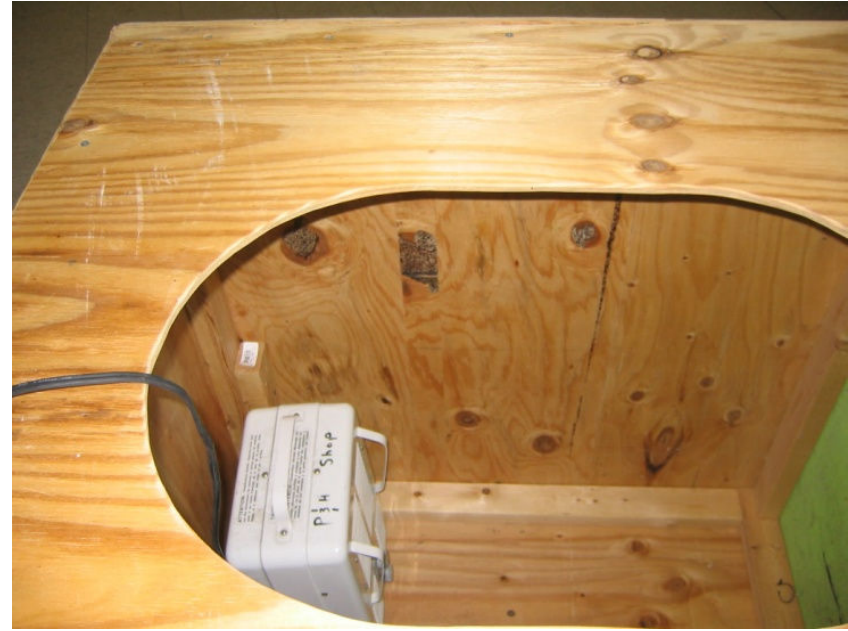

Figure 8 A space heater with integrated fan is used, however any small space heater may be suitable.

\section{Class exercise}

The class exercise is included in Appendix 1. Since the subject students have not had a heat transfer course, basic relations are provided. Steady state conditions are assumed, therefore application of the first law and Fourier's law predicts the electric power entering the box will equal the heat exiting the box by conduction and convection once a steady state temperature distribution is achieved. Students are asked to guess values for the steady state temperature in the box. They are then asked to estimate the temperature using the given relations.

When calculations are complete the results are listed and the demonstration is started. The space heater is switched on, and the class monitors the current, voltage, and temperatures. In this case a handheld data acquisition system, with a time versus temperature chart, was used. This allowed instructors to better discuss the difference between transient and steady state behavior.

Material properties and convection coefficients were estimated using typical values for similar cases. For students with a background in heat transfer, the estimation of these parameters may be included in the assignment. A thermal conductivity of $0.1 \mathrm{~W} / \mathrm{mK}$ was assumed for the plywood. 
The internal and external convection coefficients were assumed to be $500 \mathrm{~W} / \mathrm{m}^{2} \mathrm{~K}$ and $50 \mathrm{~W} / \mathrm{m}^{2} \mathrm{~K}$ respectively, yet these may overestimate the actual values. These assumptions yielded reasonable predictions.

\section{Results}

Assuming the given parameters, with a $20^{\circ} \mathrm{C}$ ambient temperature outside the box, the steady state temperature in the box is estimated to be $58^{\circ} \mathrm{C}$. During demonstrations the actual steady state temperature was found to be within $+/-7^{\circ} \mathrm{C}$ of this value. Instructors discussed the impact of the assumptions on result accuracy with the students, who were encouraged to see the value in using equations to quickly make predictions. Student guesses varied significantly, between $30^{\circ} \mathrm{C}$ and $100^{\circ} \mathrm{C}$. The authors discovered that some students did not comprehend the concept of steady state temperature distributions, and assumed the temperature would continue to rise in the box. After the demonstration, students seemed to have a stronger grasp of the first law and basic heat transfer concepts involved.

\section{Piston cylinder and boundary work}

A piston air cylinder and cylindrical accumulator are charged with an air compressor for the purpose of demonstrating the concepts of conservation of mass, the ideal gas law, boundary work, and the conservation of energy.

\section{Description}

System components are mounted on a common base as shown in figure 10 . The system includes a Rietschle Thomas 12 V DC, 10 A, thermally protected compressor, model 405ADC38/12, powered by a small 12V DC battery. The compressor retails for just under three hundred dollars. This device was readily available, yet any compressor capable of charging the accumulator to the desired 85 psig would be suitable and may reduce cost.

A Bimba manufacturing company model 3112-DXP air cylinder is mounted to the wood base as shown in figure 11. The device retails for just under sixty dollars, and is bidirectional, with a 12 inch stroke and 2 inch bore. It was used during a recent FIRST robotics competition, and was therefore conveniently available. Figure 9 shows the quick connect valves which allow for convenient air tube configuration. The actuator arm is fitted with an Aluminum platform for supporting applied loads. A light weight length of plastic, with graduated dimensions, may be attached to the platform for the purpose of rapidly measuring piston travel.

A 2.5 inch diameter, $12 \% 3$ inch long, accumulator, fitted with a pressure gauge, is also mounted on the base. The dimensions given here are nominal, and were quickly estimated in class. Greater accuracy in the dimension estimate was deemed unnecessary given the degree of uncertainty surrounding other assumptions on system characteristics. 


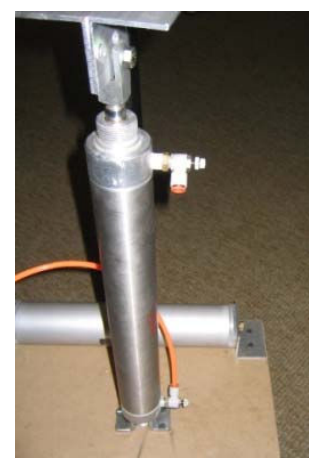

Figure 9 Piston cylinder with valves mounted on the right.

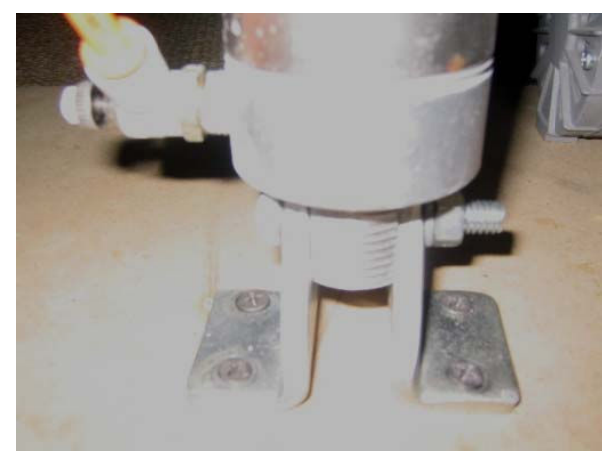

Figure 11 Piston cylinder mounting bracket.

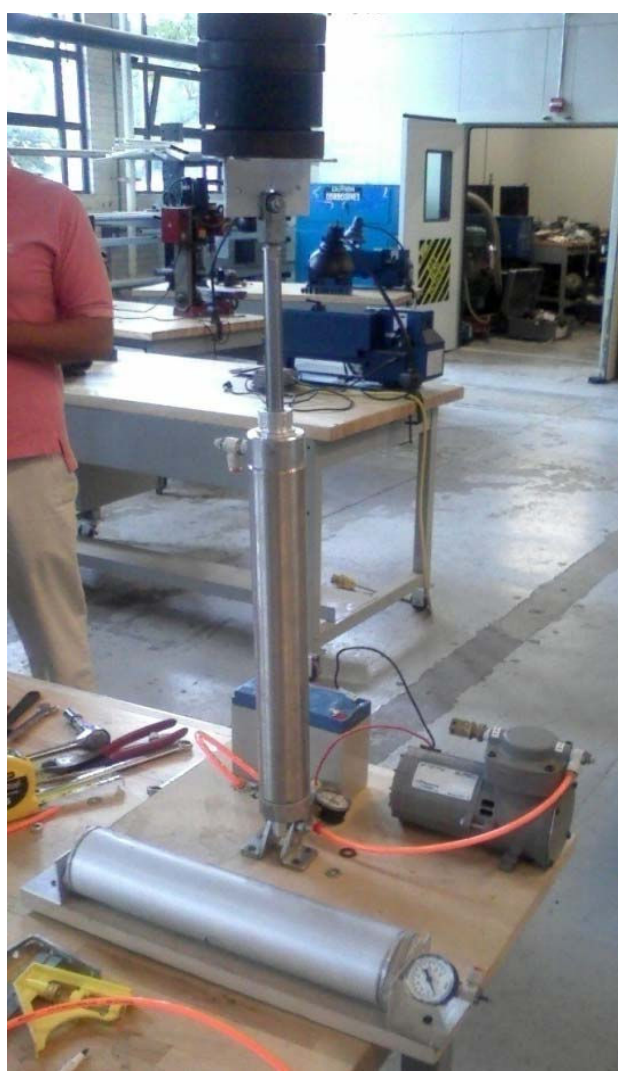

Figure 10 Demonstration system.

\section{Class exercise}

The assignment handout is included in Appendix 2. Students are shown the device and given a brief description of the components. The handout provides dimensions, useful assumptions, and exercise steps.

The first exercise explores the ideal gas law, the conservation of mass, and the conservation of energy. The piston is lifted, with no load, and the ports closed so the pressure in the cylinder supports the empty platform. Students are told a load of approximately 10 pounds will be placed on the platform, causing the piston to compress air in the cylinder. Students are instructed calculate how far the piston will descend and the resulting final pressure. An isothermal process is assumed. The final pressure can be calculated easily using statics. With the bore, and initial and final pressures, known, the final height of the cylinder can be readily found using the ideal gas law. Students may then estimate the isothermal work required to compress the gas using expressions for boundary work. The heat transferred out of the cylinder during the process may be estimated using the conservation of energy principle. The order of questions in the handout is deliberate, requiring students to recognize that some questions must be answered out of order.

For the second part of the demonstration the air under the piston is evacuated and another 10 pounds is added to the platform. The air compressor is used to charge the accumulator, mounted horizontally on the base, to $85 \mathrm{psig}$. A tube is used to connect the accumulator and piston cylinder device via the bottom port. Valves isolate the accumulator from the piston prior to the 
demonstration as indicated in figure 12. Students are asked to calculate the energy required to lift the weight to the stops using energy methods. They are then asked to estimate the boundary work required to do this, assuming a constant pressure process. Students must recognize that the lifting process will be isobaric as long as the weights are lifted slowly and the stops are not reached. Students then calculate the equilibrium pressure which will be achieved if the lower valve is opened after the piston reaches the upper stops. This simple exercise requires use of the ideal gas law and convenient control volumes. The final question asks students to consider why the pressure changes in this last step if no work is done. This creates a discussion point leading into the topic of entropy, the next scheduled lecture in the course.

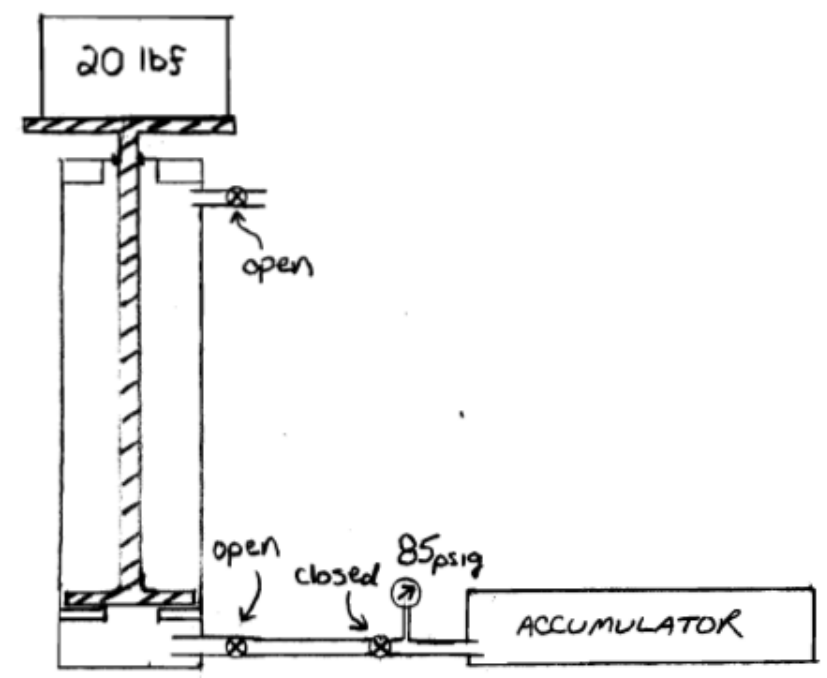

Figure 12 Configuration for part two of the exercise. The valve on the right may be opened to raise the weight.

Results

Reasonably accurate results may be obtained with the given assumptions. Measured piston travel during the first exercise was consistently within $1 / 4$ inch of the calculated value. The final pressure in the accumulator was consistently measured within $1 \mathrm{psig}$ of the calculated value. The unit is not yet designed to verify heat transfer characteristics investigated during the exercise.

\section{Reflections and Results}

Student reaction to particular exercises was not assessed. The demonstrations were used in combination with homework assignments designed to highlight the practical application of the course. Homework problems included the analysis of an automobile turbocharger and internal combustion engine, the sizing of a flash distillation unit for a Coast Guard cutter, and the analysis of an auxiliary gas turbine from a Coast Guard helicopter.

End of semester course feedback results were reviewed to assess overall student reaction to the course. For the semester in which these demonstration units were used both instructors were new, so there are several factors influencing the general course feedback which are not 
dependent on these exercises. The course feedback survey questions are common to all courses at the institution, so questions were not developed by the authors. The feedback reinforced the authors' personal observations. Over $95 \%$ of students participated in the surveys discussed here.

$85 \%$ of respondents agreed with the statement "I believe course material will benefit me during my career", while another $12 \%$ gave a neutral response. Selected survey results, deemed applicable to the demonstrations described, are given in table 2.

General student comments included: "I definitely see engineering problems in a new light now"; "I liked the example problems that were handed out and completed in class"; "This course was very informative and definitely contributed to what I hope to do in my career".

Table 2 Selected end of semester survey results

\begin{tabular}{|l|c|c|c|c|c|}
\hline Statement & $\begin{array}{l}\text { Strongly } \\
\text { disagree }\end{array}$ & Disagree & Neutral & Agree & $\begin{array}{l}\text { Strongly } \\
\text { Agree }\end{array}$ \\
\hline $\begin{array}{l}\text { I believe course material will } \\
\text { benefit me during my career }\end{array}$ & $0 \%$ & $3 \%$ & $12 \%$ & $58 \%$ & $27 \%$ \\
\hline $\begin{array}{l}\text { The course was academically } \\
\text { challenging }\end{array}$ & $0 \%$ & $0 \%$ & $12 \%$ & $27 \%$ & $61 \%$ \\
\hline $\begin{array}{l}\text { Emphasis was placed on the quality } \\
\text { of material, not on the quantity }\end{array}$ & $0 \%$ & $6 \%$ & $21 \%$ & $43 \%$ & $30 \%$ \\
\hline $\begin{array}{l}\text { Lessons were well organized and } \\
\text { given in a comprehensive manner }\end{array}$ & $3 \%$ & $9 \%$ & $30 \%$ & $52 \%$ & $6 \%$ \\
\hline $\begin{array}{l}\text { The instructor made effective use of } \\
\text { visual aids }\end{array}$ & $0 \%$ & $6 \%$ & $18 \%$ & $61 \%$ & $15 \%$ \\
\hline $\begin{array}{l}\text { The instructor clearly enjoyed the } \\
\text { subject matter }\end{array}$ & $0 \%$ & $0 \%$ & $15 \%$ & $56 \%$ & $30 \%$ \\
\hline $\begin{array}{l}\text { I can apply the material presented in } \\
\text { class to real life situations }\end{array}$ & $0 \%$ & $0 \%$ & $24 \%$ & $61 \%$ & $15 \%$ \\
\hline
\end{tabular}

\section{References}

[1] Gerhart, A, Gerhart, P, \& Fletcher, R. "Comparison of Differing Credit Hour Allotments for Thermodynamics and Fluid Mechanics Courses", Proceedings of the 2008 American Society for Engineering Education Annual Conference \& Exposition, Pittsburgh, PA, June 2008

[2] Edwards, R. "A Simple Hairdryer Experiment to Demonstrate the First Law of Thermodynamics" Proceedings of the 2005 American Society for Engineering Education Annual Conference \& Exposition, Portland, OR, June 2005

[3] Volino, R \& Smith, A. "A Laboratory Providing Hands-On Experience With a Spark Ignition Engine in a Required Thermodynamics Course", Proceedings of the 2006 American Society for Engineering Education Annual Conference \& Exposition, Chicago, IL, June 2006 
[4] Ardebili, M. "Active-Learning Based Laboratory for Introductory Thermodynamics Course", Proceedings of the 2006 American Society for Engineering Education Annual Conference \& Exposition, Chicago, IL, June 2006

[5] Alvarado, J. "Design Your Own Thermodynamics Experiment, a Problem-Based Learning Approach in Engineering Technology", Proceedings of the 2006 American Society for Engineering Education Annual Conference \& Exposition, Chicago, IL, June 2006

[6] Wilczynski, V. "A Virtual Instrument Based Engineering Experimentation Course", Proceedings of the 2000 American Society for Engineering Education Annual Conference \& Exposition, St Louis, Mo, June 2000

[7] Walters, D., Wilczynski, V., \& Hiles, K. "An Instrumented Egg Drop Experiment In Support of Courses in Mechanical Control and Experimental Analysis", Proceedings of the 1996 American Society for Engineering Education Annual Conference \& Exposition, Washington, DC, June 1996

[8] Plumley, M., \& Wilczynski, V. "Design Portfolios for Outcomes Assessment and Program Vision", Proceedings of the 2008 American Society for Engineering Education Annual Conference \& Exposition, Pittsburgh, PA, June 2008

[9] Dixon, G. "Three Thermal Systems Design-Build-Test Projects", Proceedings of the 2004 American Society for Engineering Education Annual Conference \& Exposition, Salt Lake City, UT, June 2004

[10] Dixon, G. "A Solar Distiller as a Thermal Systems Design-Build-Test Project", Proceedings of the 2006 American Society for Engineering Education Annual Conference \& Exposition, Chicago, IL, June 2006 


\section{Appendices}

\section{Appendix 1: Space heater class exercise handout}

A space heater with integrated fan is placed in a plywood box. The box is a cube with sides of 1 yard. The space heater is rated at $700 \mathrm{~W}$. Power is drawn from an electric outlet outside the box via a power chord. We have not covered heat transfer yet, however in this case you may assume the steady state heat loss is given by:

$$
Q_{o u t}=\frac{\Delta T}{R_{e q}}
$$

where

$$
R_{\text {eq }}=\frac{1}{h_{\text {in }} A_{\text {side }}}+\frac{\Delta x}{k A_{\text {side }}}+\frac{1}{h_{\text {out }} A_{\text {side }}}
$$

$\mathrm{A}_{\text {side }}=$ surface area of box

$\mathrm{k}=0.1 \mathrm{~W} / \mathrm{mK}$ (assumed thermal conductivity of plywood)

$\Delta \mathrm{T}=$ temperature difference between inside and outside air

$\Delta x=$ thickness of box (here approximately $1 / 2 "$ )

Assume $\mathrm{h}_{\text {in }}=500 \mathrm{~W} / \mathrm{m}^{2} \mathrm{~K}$ and $\mathrm{h}_{\text {out }}=50 \mathrm{~W} / \mathrm{m}^{2} \mathrm{~K}$. If the air inside and outside of the box, as well as the plywood, are at $20^{\circ} \mathrm{C}$ initially, and we run the space heater until the system reaches steady state, what will the temperature of the air inside the box be? 


\section{Appendix 2: Piston cylinder exercise handout}

Demo: With the help of a little imagination and our awesome lab techs (what more do you need really?) we developed the compressor, accumulator, and piston-cylinder demo you see in class. It consists of spare shop parts, so some technical data is unavailable. We should be able to come to reasonable answers to the questions given below using what we've learned in class and some rough estimates. The piston cylinder has a 12 in stroke and a 2 in bore. The accumulator has a 2.5 in diameter and a $12 \%$ in length.

We will assume many processes here are isothermal, which is valid if heat transfer is rapid enough to quickly place the working fluid (air) in equilibrium with the surroundings after the work is done. This is reasonable given the high conductivity of the Aluminum.

Exercise 1: The piston will be lifted to just below top dead center and the valve closed so that the pressure in the cylinder is equal to atmospheric pressure (plus a slight increase due to the platform and piston weight). Weights are added totaling $6 \mathrm{lb}$ and $2 \mathrm{~kg}$. (We're not kidding, that's how they're stamped, time to do some conversions!).

(a) How much will the piston descend after the weights are added? Assume an isothermal process.

(b) What will the final pressure in the cylinder be?

(c) Should heat be transferred in or out of the cylinder during this process?

Exercise 2: Now we'll charge the cylinder and use it to lift a $20 \mathrm{lb}$ weight. The accumulator acts like a capacitor, storing energy for us until we need it. First, we'll charge the cylinder to __ psig (will be around $85 \mathrm{psig}$ ). Then we'll attach the tube to the piston cylinder lower port. A valve initially separates the accumulator from the piston cylinder.

(a) How much work is required to raise the weight to the full height? (hint: use 'energy methods')

(b) What is the boundary work required to raise the weight to full height assuming we raise it 'slowly', so that acceleration is negligible?

(c) Why is it important to assume negligible acceleration in the last question?

(d) What will the pressure be in the accumulator when the weight just reaches its full height? (We'll open the valve until weight goes up, then quickly close it to measure pressure before it hits the stops)

(e) What will the pressure in the piston cylinder be when the weight just reaches its full height?

(f) What will the pressure in the accumulator be if we then open the valve all the way, allowing equilibrium to be reached?

(g) For the process described in the last question there is no work being done, yet the pressure changes. How do we account for this? 